\title{
PERFORMANCE OPTIMIZATION OF A THREE PHASE INVERTER THYRISTOR
}

\author{
Ndjiya Ngasop ${ }^{1 \text { et } 2}$ and Haman-Djalo ${ }^{3}$ \\ ${ }^{1}$ Department of Process Engineering National School of Agro-Industrial Sciences \\ (ENSAI), University of Ngaoundere, Cameroon
}

${ }^{2}$ Department of Electrical Engineering, Energetics and Automation, National School of Agro-Industrial Sciences (ENSAI), University of Ngaoundere, Cameroon.

${ }^{3}$ Department of Physics, Faculty of Science, University of Ngaoundere, Cameroon.

\begin{abstract}
Static converters are used in various fields of the conversion of electrical energy. The important development of electric power switches and variety of design techniques of control and regulation circuits bring very advantageous solutions for congestion, reliability, performance and maintenance of converters. This work focuses on optimizing the performance of a thyristor three-phase inverter, and its association with a photovoltaic generator for the purpose of operating a maximum power delivered by the latter. The nature of the control of electronic switches allows to optimize the performance of a three-phase inverter thyristors, using a percentage of the open circuit voltage of a solar panel driver. The operation control system helps to operate at maximum power of the photovoltaic system.
\end{abstract}

\section{KEYWORDS}

Controlled rectifiers, Electrical Energy Optimization, Effective Management.

\section{INTRODUCTION}

Since the control of electromagnetic phenomena explained and formalized by the Maxwell equations, we know that electricity is produced using rotating magnetic fields. A retrospective and contemporary look of our society shows us that the developed countries had their economic, social and infrastructural prowess through industrialization itself dependent on energy sources and more specifically, production, transport and wide distribution of electrical energy [2],[3], [5], [8] and[11]. This energy produced in hydro power plants or turbine has a form of fixed sine wave amplitude and frequency. It should then be transported and distributed to its various users. As difficulty, there is the waveform produced and sent to subscribers do not always correspond to that required by various installations of the subscriber [21] and[6]. Hence the need to install conversion devices of the waveform of the distributor that desired by the facilities once the energy produced and delivered to the user. Thus talk of conversion devices rectifiers, choppers, inverters, controllers and cyclo converters [4], [9],[12], [13], [14], [16], [19], [20] and [21]. By

DOI : 10.14810/elelij.2015.4404 
placing us only in the field of processing of electrical energy after production, we will throughout this work to limit ourselves to electrical conversion waveforms in other words, on the possibilities of generating at the industrial and domestic scale, alternative electrical energy (amplitude and frequency variable) using of any DC source [7], [18] and [9]. Because the distributors of electrical energy supply only energy sinusoidal AC waveform is fixed in amplitude and frequency, there arises firstly at the enterprise level and domestic installations multiple issues and challenges we have the right to ask: how to change the waveform of the distributor in a form of variable wave amplitude and frequency? How to have recourse to an emergency power supply in case of failure of the distributor network? On the other hand, knowing that for an $\mathrm{AC}$ motor that the speed depends on the amplitude and frequency of the voltage applied to its terminals, it begs the question of how to regulate and control this speed when we know that it can not be fixed as long as it remains powered by a fixed network in amplitude and frequency?

In areas of sensitive activities such as hospitals where one does not want a power failure, it is also the question of how to address the problem of breaking any distribution network at least in sensitive blocks such as the operating room?

Multiple solutions can be proposed for each of the issues raised but, as part of this work, we will limit ourselves to those proposed by the power electronics. Indeed, for its various concerns, the development of power electronics is dependent on the physics of semiconductor devices to provide a solution by simply inserting an inverter between the power source and the load. However, we do not limit ourselves to the insertion of an inverter with the aim to answer our questions, but much more, we will focus throughout the work on the optimization of a performance thyristor three-phase inverter. This article in its joints, first presents the material basis and methods which details the specific study of several inverters to make a wise choice from that which we propose to scale it and optimize it, then As results and discussion of the simulation of the three-phase autonomous inverter thyristors followed by a critical comparison with those of devices presented by the literature and finally the conclusion.

\section{MATERIALS AND METHODS}

\subsection{Material}

As part of this work, we used the integrated software in MATLAB Simulink saw a possible optimization.

\subsection{Methods}

To conduct a critical analysis of our three-phase inverter, perform the dimensioning of a power inverter circuits.

\subsubsection{Sizing and Selection of thyristors and freewheel diodes}

In electronics, the design is defined as all the calculations that are made for the selection of a component from the array of existing ones similar to insert it wisely in the scheme of making a system design. The design of a three-phase inverter $3 \mathrm{~kW}$ primarily relies on the knowledge of its output characteristics. 


\subsubsection{RMS current calculation supported by each thyristor}

The trick is to pay attention to an operating state of the system. If the inverter must produce an output power $\mathrm{P}$, we say immediately that for a load coupled star and a DC supply voltage $\mathrm{U}$, the rms current in each phase will be deducted from the $P=3 V_{l} I \cos \varphi$ where $V_{l}$ is the effective value of the fundamental of the output voltage between Phase $V_{1}=U \frac{\sqrt{2}}{\pi}$.

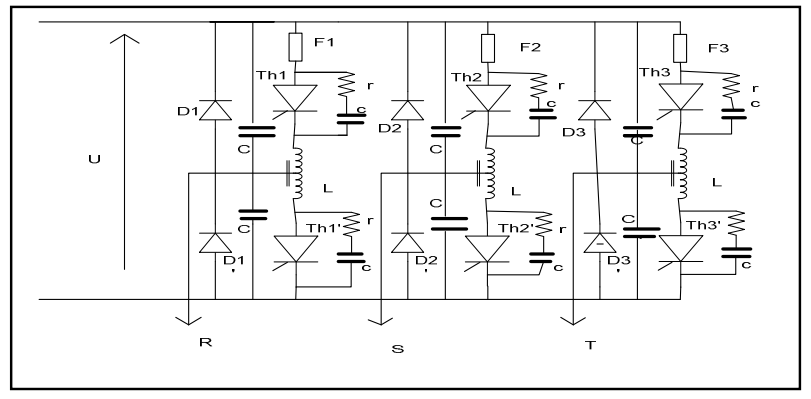

Figure 1:Complete Mounting phase extinction circuit LC extinguishing circuit.

Taking $\cos \varphi$ known, is obtained:

$$
I_{\text {eff }}=\frac{\pi P}{3} \sqrt{2} U \cos \varphi
$$

Hence the average value of the current intensity through each switch:

$I_{T h}=I_{e f f} \sqrt{2} \frac{(1+\cos \varphi)}{\pi}$ equivalent to the average current that the semiconductor leaves for a past period.

For a delta connection where we should have a voltage between phase equal to the effective voltage.

So during operation of the system, each thyristor will be able to let through an effective current which is an essential characteristic without the temperature of its junction is scope to that destruction. It is also easily deduced that the peak current that provide the inverter to the load, once it is passed through the thyristors $I_{\text {eff }} \sqrt{2}$.

\subsubsection{Determination of $V_{A K}$ voltage Max in the off state}

The three-phase voltage inverter power $\mathrm{P}$ supplied by a DC voltage $\mathrm{E}$ is such that:

- The positive voltage than the thyristor can withstand live, when blocked is greater than $\mathrm{E}$. It is desirable to take $\mathrm{V}_{\mathrm{AK} \text { Max }}>\mathrm{E}$.

- The negative voltage that can support the thyristor in reverse when locked equals $\mathrm{V}_{\mathrm{AK} \text { Max }}$ in absolute value. It is desirable to take $\mathrm{V}_{\mathrm{AK} \text { inv Max }}<-\mathrm{E}$. 
In short, the choice of thyristors for which the voltage values $\mathrm{V}_{\mathrm{AK} \text { Max }}$ et $\mathrm{V}_{\mathrm{AK} \text { inv MAX }}$ are lower in absolute terms than the supply voltage E will help us to uncontrolled Arcing or destruction of thyristors breakdown.

\subsubsection{Determining the control characteristics}

The thyristor starting circuit will be almost identical to that proposed by Ndjiya et al.(2014) [9].

\subsubsection{Sizing and Selection of freewheeling diodes}

Having assumed in the theoretical analysis that the current in the load is sinusoidal shape $I^{\prime}(t)=I \sqrt{2} \sin \omega t$ and analysis of different voltages and timing out of current shows that for each inverter, each freewheeling diode is conducting every time the forward current of the corresponding thyristor tends to be canceled. Thus, the choice of our free-wheeling diodes, a constraint depend running three times lower than that of thyristors, ie: $I_{\text {eff } D}=I_{\text {eff }} / 3$.

Their tensile stresses will remain equal to those of the thyristors, view them in antiparallel to the thyristors. $\mathrm{V}_{\mathrm{AK} \text { Max }} \mathrm{E}$. diodes will therefore be greater than the voltage of the DC power source $\mathrm{E}$.

\subsubsection{Calculation of protection devices against surges and currents}

The protection of semiconductor switching devices against surges is done through an RC circuit that we have parallel component to protect. The calculation of these components, should take account of RC time of the order. $\mathrm{t}_{\mathrm{q}}$ being of the order of $40 \mu \mathrm{s}$ for the fastest power thyristors, we have chosen for our calculations from $1 \mathrm{t}_{\mathrm{q}}$ to $100 \mu \mathrm{s}$ that a fast thyristor will be more suited to a UPS with oscillating quenching circuit which actually presents some difficulties operating at high frequencies[10].

\subsubsection{Calculation of extinction circuit}

For our study, we focused our choice on an extinction circuit LC oscillating circuit [9]. We have the ability $C_{1}$ se charge in the voltage $U$ during conduction de $T_{h 1}$. When closing $T_{1}, L_{1} C_{1}$ circuit drives the oscillatory discharge of $\mathrm{C}_{1}$ through $\mathrm{T}_{\mathrm{h} 1}$. Later this discharge beingi $\mathrm{i}_{\mathrm{c}}=$ $U C \omega \sin \omega t$ where $\omega=1 / \sqrt{\mathrm{LC}_{1}}$. The voltage across the lower half of the inductance.

Ldi/dt $=U \cos \omega t$, created on the $\mathrm{T}_{\mathrm{h} 1} \mathrm{~K}$ cathode potential $2 U \operatorname{Cos} w \mathrm{t}$ while its anode is at a potential U.This outcome is the current peak of this potential difference will produce the locking $\mathrm{T}_{\mathrm{h} 1}$. Therefore, $\mathrm{V}_{\mathrm{A}}-\mathrm{V}_{\mathrm{K}}=\mathrm{U}-2 \mathrm{U}$ coswt. This tension, negative, tend to turn positive again after some time, passing of course zero. Th1 remains blocked until the voltage remains above its cathode $\mathrm{U}$. Let $\mathrm{t}_{\mathrm{k}}$ the time when we will have $V=>\mathrm{t}_{\mathrm{K}}=7 \pi / 3 \omega=7 \pi \sqrt{\mathrm{LC}_{1}} / 3=7 \mathrm{~T}_{0} / 6$ with $\mathrm{T}_{\mathrm{o}}$ is the natural period of the LC circuit.

This means that $T_{h 1}$ tend to become conductor from the moment $t_{k}$. It will choose $t_{k}$ at least equal to the time for defusing $s t t_{h 1}$ does reboots.

wheret $_{\mathrm{K}} \geq \mathrm{t}_{\mathrm{q}}=>2 \pi \sqrt{\mathrm{LC}_{1}} \geq \frac{6 \mathrm{t}_{\mathrm{q}}}{7}$.

Definitely, the LC extinguishing system must be calculated so that its own period is greater than or equal to Where $0.86 \mathrm{t}_{\mathrm{q}}$. 


\section{RESULTS OF THE SIMULATION}

The simulations conducted tests show the timing of each of the components of the logic circuit of switching aid and our DC converter switches - Alternative. These timing diagrams are strictly identical to those required in theory [9], [10].

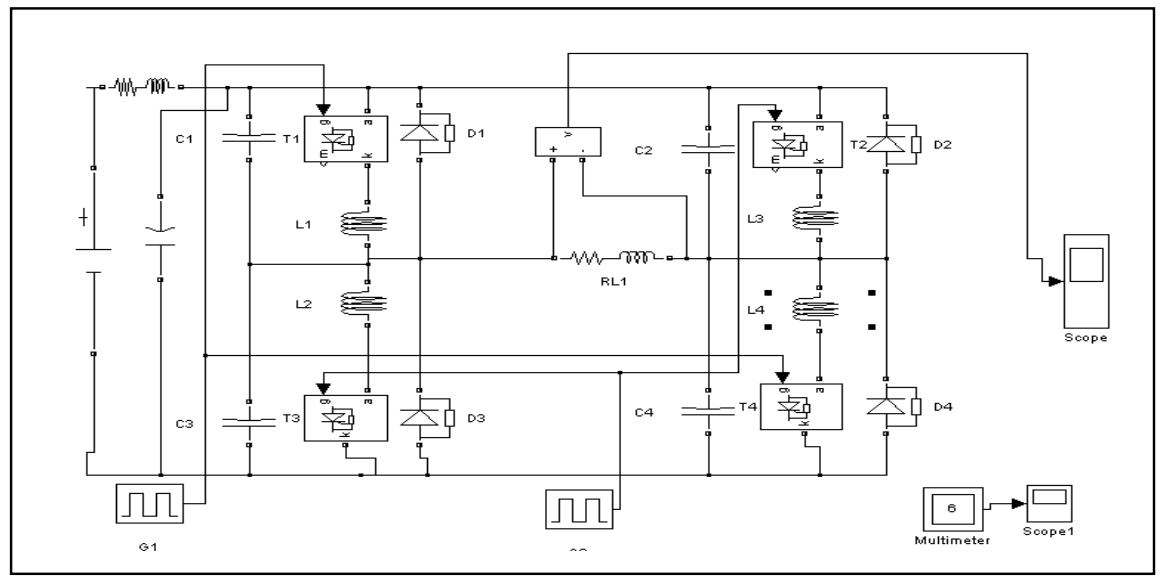

Figure 2: Circuit power of a single phase inverter unshifted control.
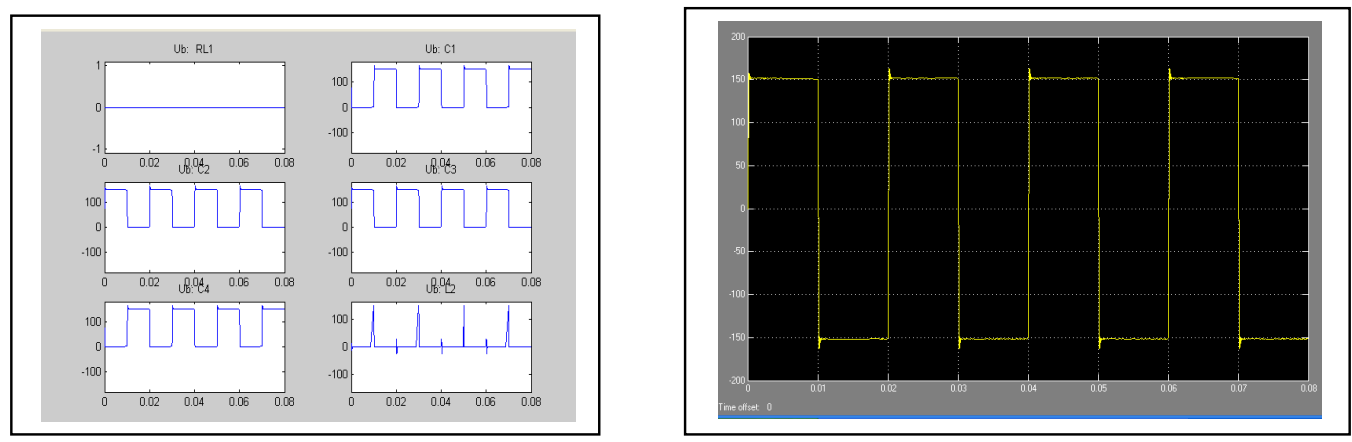

Figure 3:Timing diagram of different voltages across the various components of powers.

The results of this simulation are identical to the voltage $\mathrm{E}$ between 100 and $600 \mathrm{~V}$ with the only difference that the oscillation inductors have increased from $0.02 \mathrm{H}$ to $0.002 \mathrm{H}$ when $\mathrm{E}$ becomes greater than $300 \mathrm{~V}$.

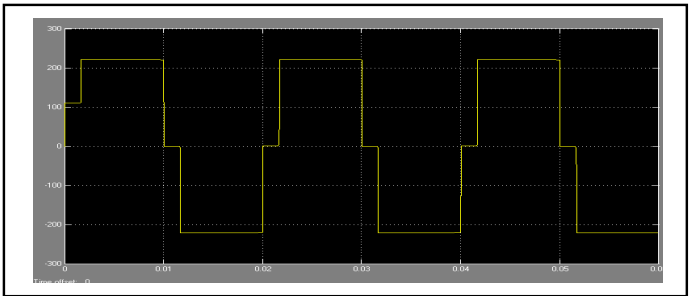


Electrical and Electronics Engineering: An International Journal (ELELIJ) Vol 4, No 4, November 2015

Figure 4: Output voltage of a single phase inverter to offset command.

Single-phase simulations so far are of a very central importance since they allow us to easily deduce the phase assemblies. Indeed, keeping the same component values calculated for the single-phase structures and, by carefully calculating the control angles for the three-phase case, we get approximately the same results. The assembly for simulating a three-phase inverter thyristor is represented below:

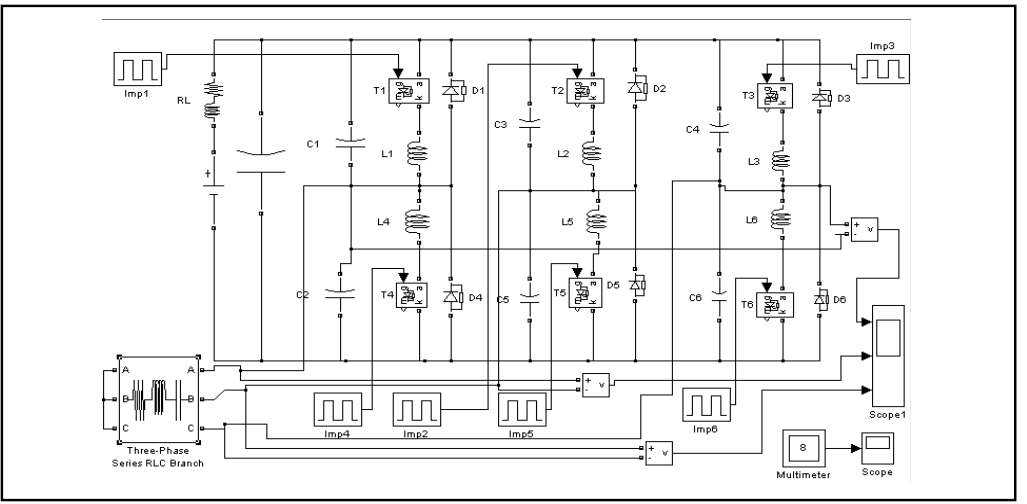

Figure 5: Simulation of a staggered three-phase inverter control.

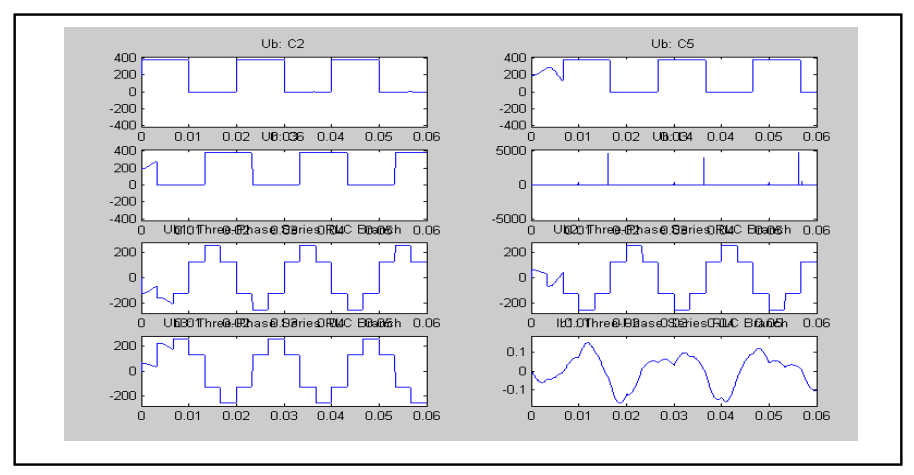

Figure 6: Simulation results of a three-phase inverter control offset.

If above the current is obtained for a three-phase load coupled star therefore the values $\mathrm{R}=3 \Omega, \mathrm{L}$ $=3 \mathrm{H}, \mathrm{C}=1 \mu \mathrm{F}$ an impedance $\mathrm{Z}$ load $=2.243 \mathrm{~kW}$. Because the current in the load depends on the nature thereof, the same three-phase inverter has been sized to produce a sinusoidal voltage output system by taking the period of oscillation of the resonant circuit RC substantially equal to $0.02 \mathrm{~s}$ that is to say $T_{0}=2 \pi \sqrt{L_{i} C_{i}}$. Results of the simulation for $\mathrm{L}_{\mathrm{i}}=0.1 \mathrm{~L} \quad \mathrm{C}_{\mathrm{i}}=1 \mu \mathrm{F}$ are as follows: 

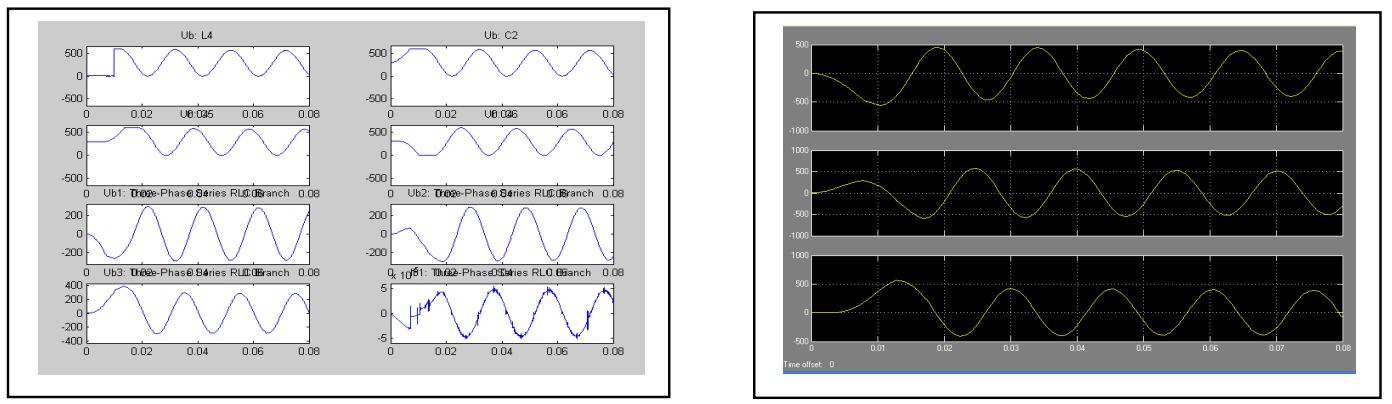

Figure 7: Results of the simulation of a three-phase inverter control shifted to $\mathrm{Li}=0.1 \mathrm{~L}$ and $\mathrm{Ci}=1 \mu \mathrm{F}$ and three-phase voltage system to display the output of the inverter.

Similarly we resized $\mathrm{R}$ and $\mathrm{L}$ for a sinusoidal current maximum value equal to $5 \mathrm{~A}$ is obtained for a three-phase load coupled star and value per phase equal to: $\mathrm{R}=2 \Omega, \mathrm{L}=0.003 \mathrm{H}$; or to a phase impedance $\mathrm{Z}=2.74 \Omega$ so as to model an asynchronous motor. We also introduced a capacitance $\mathrm{C}=0.5 \mathrm{nF}$ in series with the load. In addition we have also modeled our expense by an asynchronous motor impedance $\mathrm{Z}=2+0.3 \mathrm{j}$. For this it was necessary that we resize the inductors $\mathrm{L}_{\mathrm{i}}$ and $\mathrm{C}_{\mathrm{i}}$ capacitors. Optimum responses were obtained for $\mathrm{L}_{\mathrm{i}}=0.35 \mathrm{H}$ and $\mathrm{C}_{\mathrm{i}}=2600 \mu \mathrm{F}$.

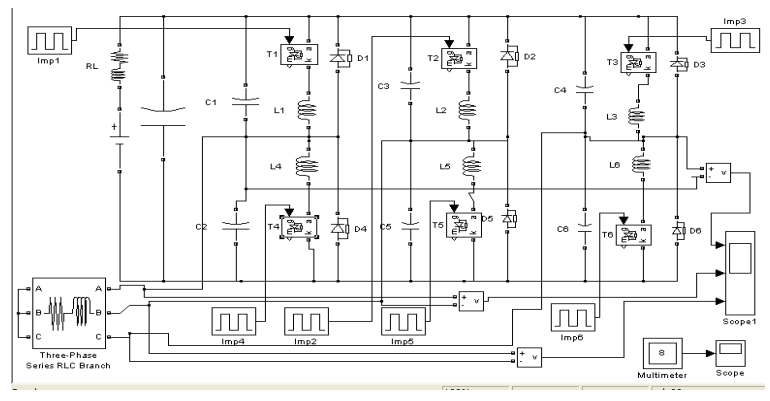

Figure 8:Modeling of the power circuit of a three-phase inverter feeding an asynchronous motor.

The voltage source $\mathrm{E}$ that we have used so far is constructed from the industrial network as shown in the diagram below if. Lowering the voltage from an alternator $25 \mathrm{~kW} / 60 \mathrm{~Hz} / 10 \mathrm{kVA}$ by a transformer of $25 \mathrm{kV} / 600 \mathrm{~V} / 60 \mathrm{kVA}$. The voltage thus obtained is rectified by a rectifier bridge followed by a capacitive and inductive filtering. The answer to this voltage source is represented by the diagram below.

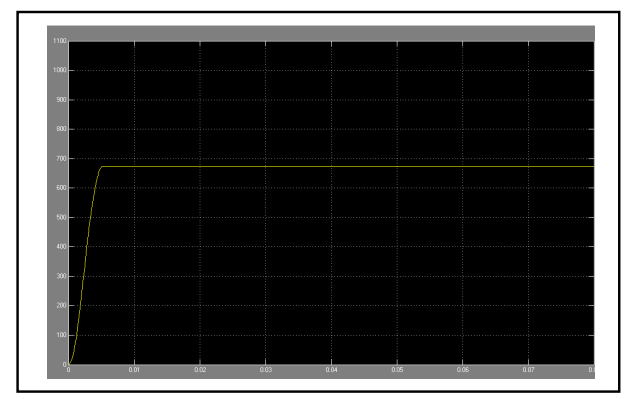


Electrical and Electronics Engineering: An International Journal (ELELIJ) Vol 4, No 4, November 2015

Figure 9: Rectified voltage for supplying the three-phase inverter.
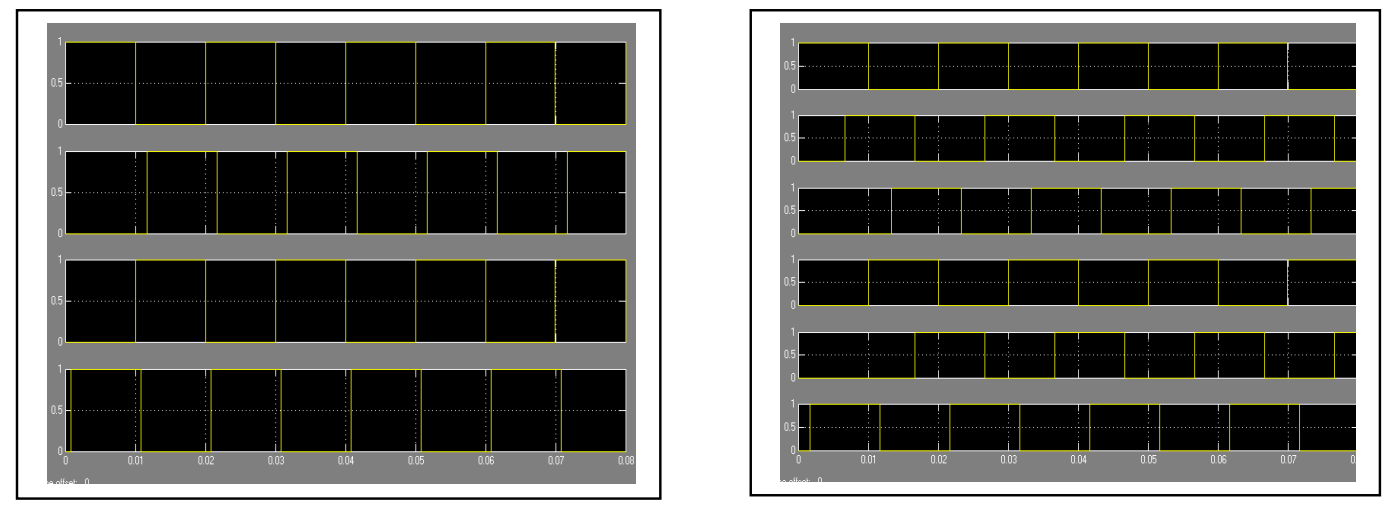

Figure 10: Timing diagrams viewed from the shifted control of single phase and three phase.

\section{CONCLUSION}

This paper presents the command of an autonomous tree phase like single phase converter with shifted command used to stabilize the energy produced by the photovoltaic cells. The presented control system was tested in the laboratory. The results are satisfactory, but it remains to realize the three-phase inverter in order to supply as an asynchronous motor actual load to enjoy the direct association of the solar generator. This shifted command aids in modifying the characteristics of the output voltage,particularly the effective value of its fundamental without involving the continuous voltage of its energy supply. In multiple applications, it can be used in the energy supply of sensible devices like non synchronous machines. When this is jointed to a pump, it can produce drinking water by a tangential ultrafiltration unit of water with a perforated fiber or a unit of desalinated water.This will see how to use the offset command performed to deduce that of the phase.

\section{REFERENCES}

[1] Agati P., Electricité Electronique (de commande de puissance). Electrotechnique, 1ère Édition, DUNOD, Paris- France, pp. 139-146, 1997.

[2] Bhende C. N., Mishra S. and Jain S. K., "TS. Fuzzy-controlled active power filter for load compensation',. IEEE, T Power delivery, Vol 21, No.3, July 2006, pp. 1459-1465.

[3] Champenois A., Alimentations Thyristors et Optoélectronique. 1ère édition, Edition du renouveau pédagogique, INC, Canada, pp. 289-402, 1988.

[4] Coeurdacier S., Electronique (les composants discrets non linéaires). Dunod, Paris, pp. 205-257, 1979.

[5] Dalmasso J.L., Traitement de l'énergie électrique (convertisseurs statiques). Technique supérieur, France, PP: 341-357, 1988.

[6] EL. Kholy E. E., EL. Sabbe A., EL. Hefnawy A. and HamdyMharous M., "Three-phase active power filter based on current controlled voltage source inverter'. EPES 28, ELSEVIER, 2006, pp. 537-547.

[7] Fogelman T., Systèmes photovoltaïques pour les pays en développement. Marseille, France, 231 P, 1982.

[8] Guan-ChyunHsich, and Hung James C., "Phase-Locked Loop Techniques-A Survey'. IEEE, T Ind. Electronics, Vol.43, No.6. December 1996, pp. 609-615.

[9] Haman-Djalo, Ndjiya Ngasop, Nso Emmanuel and Kayem Joseph,Etude et Réalisation d'un Onduleur Autonome à circuit de commande Mc Murray Bedford, International Journal of Sciences and 
Electrical and Electronics Engineering: An International Journal (ELELIJ) Vol 4, No 4, November 2015

Innovation (IJSI). ISSN 2028-9324 Vol. 3 No. 2, pp. 517-527, June 2013.

[10] Krishna Kantha Ch., DeepthiSree P., "Analysis, Simulation \&Comparison of Various Multilevel Inverters Using Different PWM Strategies,” IOSR Journal of Electrical and Electronics Engineering, Vol. 9, no. 2, PP 54-65, 2014.

[11] Lander C. W., Electronique de Puissance. 2ème édition, McGraw-Hill, Paris, P. 147-150, P. 191-197, P. 174-175, 1989.

[12] Malesani L., Mattavelli P., Tomasin P., "High-Performance Hysteresis Modulation Technique for Active Filters', IEEE, APEC, San Jose, CA USA. Vol.2, 3-7 March 1996, pp. 939-945.

[13] Merat R., Moreau R., Allay L., Dubois J.P., La Fargue J. et Le Goff R., Electronique de puissance. Nathan, Paris, PP : 1-78, 1984.

[14] Perez-Mas et Fouchet, Electronique Pratique.1ère édition, BORDAS, Paris, pp. 190-199, 1984.

[15] Pierre Agati, Electricité, Electronique (de commande de puissance) et Electrotechnique. 1ère édition, DUNOD, Paris-France, pp. 43-78, 1997.

[16] Ramirez V., Physiques des semi-conducteurs. Bordas, Paris-France, pp. 4-69, 1980.

[17] Raymon M. et Marton, 110 Etudes pratiques à semi-conducteurs. Eyrolles, Paris, France, pp. 4-69, 1983.

[18] Rodriguez I. E., Bernet J., Steimer S., Lizama P. K., “A Survey on Neutral-Point-Clamped Inverters,” IEEE Transactions Industrial Electronics, vol. 57, no.7, pp. 2219 - 2230, 2010.

[19] Séguier G., Les Convertisseurs de l'Electronique de Puissance - La Conversion Continu- Continu. Ed. Tech. \& Doc., Tome 3, 1987.

[20] Sivasankari S. and Balamurugan C. R., "Embedded Controller Based Multilevel Inverter Topologies," Electrical and Electronics Engineering: An International Journal (ELELIJ), Vol. 3, no. 2, pp. 81-89, 2014.

[21] Tripathi A., "Comparative analysis of fixed and sinusoidal band hysteresis current controllers for voltage source inverters". IEEE Trans on IE, Vol.39, N.1, February 1992, pp 63-73. 